\title{
Banco de Sementes de Plantas Daninhas em Solo Cultivado com PASTAGENS DE Brachiaria brizantha E Brachiaria humidicola DE DIFERENTES IDADES ${ }^{1}$
}

\author{
Weed Seed Bank in Soil Cultivated with Pasture of Brachiaria brizantha and \\ Brachiaria humidicola of Different Ages
}

SILVA, D.S.M. ${ }^{2}$ e DIAS-FILHO, M.B. ${ }^{3}$

\begin{abstract}
RESUMO - Estudou-se o banco de sementes do solo de uma pastagem de Brachiaria brizantha com 4 anos de idade e de pastagens de Brachiaria humidicola com 4, 15 e 20 anos de idade, localizadas no nordeste do Estado do Pará. Objetivou-se avaliar a influência da espécie forrageira e da idade da pastagem no tamanho e na composição do banco de sementes de plantas daninhas do solo. Cada pastagem foi dividida em cinco áreas de aproximadamente $500 \mathrm{~m}^{2}$, sendo retiradas, de cada área, 10 subamostras de solo na profundidade de $0-10 \mathrm{~cm}$. Cada amostra composta das 10 subamostras de solo foi homogeneizada, identificada, distribuída em bandeja de plástico e levada para germinar em casa de vegetação durante um período de 15 meses. O banco de sementes do solo da pastagem de $B$. brizantha foi em torno de 10 vezes menor que o da pastagem de $B$. humidicola de mesma idade. Com relação ao efeito da idade da pastagem, entre as pastagens de B. humidicola, o banco de sementes foi menor naquela de 20 anos de idade ( 1.247 sementes $\left.\mathrm{m}^{-2}\right)$, não tendo sido detectada diferença significativa entre as pastagens de 15 (11.602 sementes $\mathrm{m}^{-2}$ ) e 4 (9.486 sementes $\left.\mathrm{m}^{-2}\right)$ anos de idade. As famílias botânicas Cyperaceae, Rubiaceae e Labiateae foram as de maior predominância entre as plantas daninhas infestantes da área, em todos os tratamentos estudados.
\end{abstract}

Palavras-chave: germinação, diversidade vegetal.

ABSTRACT - The objective of this work was to study the soil seed bank of a four-year-old Brachiaria brizantha pasture soil, and in pasture soils offour, 15 and 20 year-old Brachiaria humidicola, in northeastern Pará, Brazil, to evaluate the influence of the forage species and pasture age on weed seed bank size and composition. Each pasture area was divided into five plots of about $500 \mathrm{~m}^{2}$, from which 10 soil sub-samples were collected at a depth of $0-10 \mathrm{~cm}$. The soil from each plot was mixed, identified, placed in plastic trays, and put to germinate in a greenhouse during a 15-month period. The seed bank of the four-year-old $\boldsymbol{B}$. brizantha pasture soil was about 10 times smaller than that in the four-year-old $\boldsymbol{B}$. humidicola pasture. Among the B. humidicola pasture, the effect of pasture age showed that the weed seed bank was smaller in the 20-year-old pasture (1,247 seeds $\left.\mathrm{m}^{-2}\right)$. No significant difference could be detected between the 15- (11602 seeds $\mathrm{m}^{-2}$ ) and the four-year-old (9486 seeds $\mathrm{m}^{-2}$ ) pastures. The botanical families Cyperaceae, Rubiaceae and Labiateae were the most predominant among the weeds infesting all studied treatments.

Key words: germination, plant diversity.

Recebido para publicação em 2/4/2001 e na forma revisada em 2/7/2001.

Bióloga, M.S., UFPa/Embrapa/CIRAD, Tv. Mauriti, 1013, 66080-650 Belém-PA. ${ }^{3}$ Eng.-Agrônomo, Ph.D., Embrapa Amazônia Oriental, Cx. Postal 48, 66017-970 Belém-PA. Bolsista do CNPq, <moacyr@cpatu.embrapa.br>.

Planta Daninha, Viçosa-MG, v.19, n.2, p.179-185, 2001 


\section{INTRODUÇÃO}

As gramíneas forrageiras do gênero Brachiaria são de grande importância nos trópicos e, particularmente, no Brasil (Argel \& Keller-Grein, 1996). As espécies B. brizantha e B. humidicola mostram alto grau de adaptação à região amazônica, por apresentarem crescimento agressivo, resultando em eficiente cobertura do solo e capacidade de competição com plantas daninhas (Dias-Filho, 1986).

Na Amazônia, um dos mais graves problemas no manejo das pastagens é a infestação e o aumento da densidade de plantas daninhas, associados à redução na produção de forragem (Dias-Filho, 1990, 1998a).

Em regiões tropicais, a regeneração da vegetação, após a retirada da floresta, se dá principalmente por meio da dispersão de sementes oriundas de áreas próximas e do banco de sementes (Miriti, 1998; Uhl et al., 1988).

Poucos estudos têm sido desenvolvidos e publicados na literatura científica sobre a ecologia de sementes e banco de sementes em ambiente de pastagens na Amazônia (DiasFilho, 1994, 1996, 1998b, 1999; Uhl \& Clark, 1983). O conhecimento da dinâmica do banco de sementes em pastagens pode ser um importante auxílio no desenvolvimento de práticas de manejo de plantas daninhas nesse ecossistema (Buhler et al., 1997; Dias-Filho, 1990).

Este estudo objetivou determinar a densidade e diversidade de espécies de plantas daninhas presentes no banco de sementes do solo em pastagens ativas de $B$. brizantha e B. humidicola, em uma área no nordeste do Estado do Pará, bem como a influência da idade da pastagem de $B$. humidicola sobre a densidade e diversidade de plantas daninhas presentes no banco de sementes do solo.

Na formulação das hipóteses, postulou-se que, devido ao estabelecimento e hábito inicial de crescimento mais lentos, no banco de sementes de pastagens de $B$. humidicola haveria maior densidade e diversidade de espécies de plantas daninhas que em pastagens de $B$. brizantha, a qual apresenta maior velocidade de estabelecimento e de crescimento inicial, e que as pastagens mais antigas de $B$. humidicola teriam maior densidade e diversidade de plantas daninhas no banco de sementes do solo que as pastagens mais jovens desta espécie.

\section{MATERIAL E MÉTODOS}

\section{Áreas de estudo}

As áreas de estudo eram localizadas nos municípios de Castanhal e Igarapé-Açu, na região bragantina $\left(1^{\circ} 26^{\prime} \mathrm{N}\right.$ e $1^{\circ} 40^{\prime} \mathrm{S}, 47^{\circ} 24^{\prime} \mathrm{E}$ e $48^{\circ} 30^{\prime} \mathrm{O}$ ), no Estado do Pará. Estas áreas foram escolhidas por serem representativas das áreas de pastagem da região. O clima é classificado como Am, de acordo com a classificação de Köppen (Bastos, 1972). As médias das temperaturas máxima e mínima, para o ano de realização do ensaio, foram de $32,3{ }^{\circ} \mathrm{C}$ e $21,9{ }^{\circ} \mathrm{C}$, respectivamente, com pequenas variações mensais. A precipitação pluvial anual, no mesmo período, foi de $2.853,8 \mathrm{~mm}$, sendo a média mensal de $237,8 \mathrm{~mm}$. O solo é do tipo Latossolo Amarelo, caracterizado por apresentar textura média a muito argilosa.

\section{Seleção e descrição das pastagens estudadas}

Para as pastagens selecionadas, foram consideradas as espécies forrageiras, a idade das pastagens, o manejo, o controle de plantas invasoras e a cobertura vegetal destas pastagens. O estudo foi conduzido em propriedades rurais representativas da área. Foram estudadas pastagens típicas de $B$. brizantha com 4 anos de idade e de $B$. humidicola com 4,15 e 20 anos de idade. Em todas as áreas, a floresta original havia sido derrubada para o plantio de lavoura de subsistência (mandioca, milho ou feijão) no primeiro ano, e, no segundo (B. brizantha e $B$. humidicola de 15 e 20 anos, respectivamente) ou terceiro ano (B. humidicola de 4 anos), para a pastagem. O controle de plantas daninhas foi feito por meio de roçagem manual duas a três vezes ao ano - $B$. brizantha e B. humidicola de 15 e 20 anos - ou a cada dois anos (B. humidicola de 4 anos), este seguido de queima.

\section{Amostragem do banco de sementes do solo}

Cada pastagem foi dividida em cinco áreas iguais de $500 \mathrm{~m}^{2}$, distantes pelo menos $10 \mathrm{~m}$, sendo retiradas 10 subamostras até $10 \mathrm{~cm}$ de 
profundidade de cada área, que equivaleu a uma repetição. No total, cada pastagem foi amostrada 50 vezes. A coleta de solo foi feita de forma sistemática, em um desenho em forma de X, em março de 1999. As amostras do solo foram retiradas com um trado de $4 \mathrm{~cm}$ de diâmetro.

\section{Análise das amostras}

As 10 subamostras coletadas foram homogeneizadas, compondo uma amostra composta (repetição), a qual foi acondicionada em saco de plástico preto. Posteriormente, a amostra foi distribuída em uma bandeja plástica de 33 x $49 \mathrm{~cm}$ e levada para germinar em casa de vegetação, na Embrapa Amazônia Oriental, em Belém, Pará. A altura máxima de solo na bandeja foi de $3 \mathrm{~cm}$. O número de sementes vivas foi estimado através da emergência de plântulas em cada bandeja (repetição). A distribuição das amostras na casa de vegetação foi feita aleatoriamente, de forma que não favorecesse amostras ou ambientes de coleta. Foram feitas irrigações sempre que necessário, durante todo o período do estudo.

O experimento foi avaliado durante um ano, período em que houve emergência de plântulas. No caso de não identificação, ou incerteza, de alguma espécie, esta era transplantada e posteriormente identificada. A identificação e classificação foram feitas pela equipe técnica do Laboratório de Botânica da Embrapa Amazônia Oriental. Quando a emergência cessou, as amostras foram secas ao ar, revolvidas e irrigadas com uma solução de nitrato de potássio ( $5 \mathrm{mM}$ de $\mathrm{KNO}_{3}$ ), visando estimular a germinação das sementes dormentes. Depois disso, o ensaio foi avaliado por um período adicional de três meses.

\section{Análises dos dados}

O número total de sementes que resultaram em plântulas emergidas foi transformado em número de sementes vivas por metro quadrado, até uma profundidade de $10 \mathrm{~cm}$, utilizando-se a área da amostragem do trado como referência. Os dados obtidos foram submetidos à análise de variância; os efeitos dos tratamentos e das interações foram testados para significância e, quando apropriado, as médias foram comparadas pelo teste de Tukey, a $1 \%$ de probabilidade. Os dados utilizados para a análise de variância foram transformados através de Log10. A homogeneidade de variância foi testada pelo teste de Levene. Para a apresentação dos resultados, os dados foram retransformados. Nas análises estatísticas e na confecção dos gráficos, foi utilizado o programa STATISTICA, versão 5.5 para Windows (Statsoft, Inc., Tulsa, OK, EUA).

\section{RESULTADOS E DISCUSSÃO}

\section{Banco de sementes viáveis}

A Tabela 1 apresenta os valores referentes ao banco de sementes do solo nas pastagens estudadas. O banco de sementes da pastagem de $B$. brizantha com 4 anos de idade foi em torno de 10 vezes menor que o da pastagem de B. humidicola de mesma idade. É possivel especular que, em parte, esse resultado se deveu à diferença entre as velocidades de estabelecimento das duas espécies, mais lenta em B. humidicola (Dias-Filho, 1983, 1986, 1990), o que poderia ter provocado maior infestação de plantas daninhas durante a fase de estabelecimento em $B$. humidicola, uma vez que o método de formação das duas pastagens foi, de certa forma, semelhante. Pode-se ainda especular que o uso periódico do fogo, no controle de plantas invasoras na pastagem de $B$. humidicola, tenha contribuído para aumentar o tamanho de seu banco de sementes de plantas daninhas, devido ao maior tempo que o solo dessa pastagem teria ficado descoberto, quando comparado à pastagem de B. brizantha, proporcionando, assim, maior potencial de entrada de sementes na área através da "chuva de sementes" (Thompson, 1992).

Em pastagens de $B$. humidicola de diferentes idades, o banco de sementes do solo foi menor na pastagem de 20 anos, não tendo sido detectada diferença significativa entre as pastagens de 15 e 4 anos de idade (Tabela 1), não confirmando, dessa forma, a hipótese formulada de aumento do banco de sementes com o aumento da idade das pastagens de B. humidicola. Possivelmente, esse resultado ocorreu devido ao melhor controle das plantas invasoras ao longo da vida da pastagem de 20 anos de idade. 
Tabela 1 - Banco de sementes (sementes $\mathrm{m}^{-2}$ ), idade e método de controle de plantas daninhas de pastagens estabelecidas após floresta original e plantio de lavoura de subsistência (mandioca, milho ou feijão) por um ou dois anos

\begin{tabular}{|c|c|l|c|}
\hline Espécie & $\begin{array}{c}\text { Idade } \\
\text { (anos) }\end{array}$ & Método de Controle & Sementes $\mathrm{m}^{-2 *}$ \\
\hline Brachiaria brizantha & 4 & $\begin{array}{l}\text { roçagem manual } \\
\text { 2-3x/ano }\end{array}$ & $930,9 \mathrm{a}^{* *}$ \\
\hline Brachiaria humidicola & 4 & $\begin{array}{l}\text { roçagem manual a } \\
\text { cada 2 anos e queima }\end{array}$ & $9.486,7 \mathrm{~b}$ \\
\hline Brachiaria humidicola & 15 & $\begin{array}{l}\text { roçagem manual } \\
\text { 2-3x/ano }\end{array}$ & $11.602,6 \mathrm{~b}$ \\
\hline Brachiaria humidicola & 20 & $\begin{array}{l}\text { roçagem manual } \\
\text { 2-3x/ano }\end{array}$ & $1.247,8 \mathrm{a}$ \\
\hline
\end{tabular}

* Dados retransformados de $\log 10$ para apresentação.

** Médias seguidas da mesma letra não diferem entre si pelo teste de Tukey $(\mathrm{P}<0,01)$.

O tamanho médio do banco de sementes do solo nas pastagens estudadas foi superior ao encontrado por Carmona (1995) (529 sementes $\mathrm{m}^{-2}$ ) em pastagem de $B$. brizantha de aproximadamente 8 anos de idade, no Distrito Federal. Segundo esse autor, a falta de perturbação do solo, aliada à sua baixa fertilidade, condicionou um ambiente mais estável e propício apenas ao desenvolvimento de poucas espécies e poucos indivíduos adaptados a estas condições, levando a um banco de sementes reduzido.

\section{Número médio de sementes viáveis e diversi- dade botânica nas famílias no banco de sementes}

As Figuras 1 a 4 mostram a diversidade de famílias botânicas e o número médio de indivíduos (sementes viáveis), dentro de cada família, no banco de sementes do solo das pastagens estudadas. Observa-se na Figura 1 que, na pastagem de $B$. brizantha com 4 anos de idade, o número médio de indivíduos dentro de cada família variou de 15,9 a 350,1 indivíduos por $\mathrm{m}^{2}$. A família Cyperaceae, com média de 350, 1 indivíduos, foi a mais numerosa, seguida de Rubiaceae $(159,1)$, Commelinaceae $(111,4)$ e Gramineae $(95,5)$. As demais famílias apresentaram valores médios menores que 80 indivíduos por metro quadrado. A família com menor número médio de indivíduos foi Leguminosae, com 15,9 por metro quadrado.

Na Figura 2, observa-se que na pastagem de $B$. humidicola com 4 anos de idade o número médio de indivíduos nas famílias variou de 19,9 a 3.282,6 por $\mathrm{m}^{2}$. A família que apresentou o maior número médio de indivíduos foi novamente Cyperaceae $(3.282,6)$, seguida de Labiatae $(2.128,7)$, Rubiaceae $(1.233,5)$, Urticaceae $(815,7)$ e Gramineae $(636,6)$. As demais famílias apresentaram valores médios menores que 380 indivíduos por $\mathrm{m}^{2}$. As famílias com menor número médio de indivíduos foram Scrophulariaceae e Turneraceae, com 19,9 indivíduos por $\mathrm{m}^{2}$.

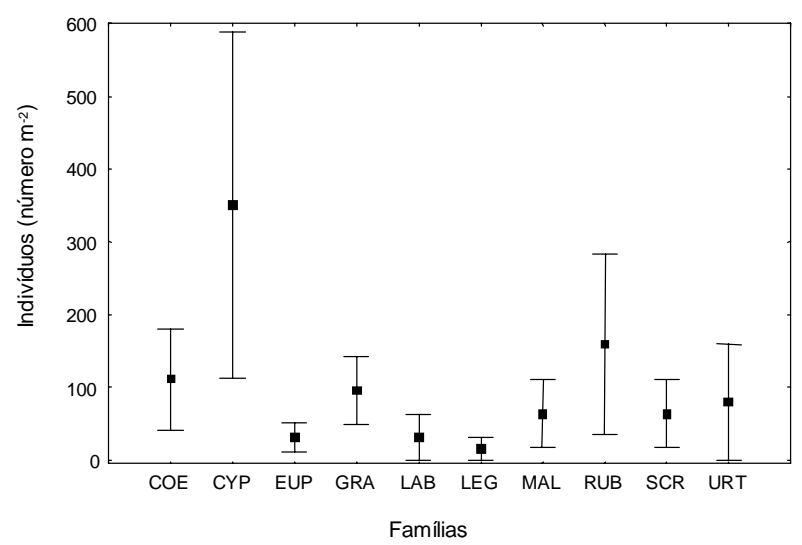

Figura 1 - Número médio de indivíduos por famílias, em pastagem de $B$. brizantha de 4 anos de idade. Valores são média \pm erro-padrão $(n=5)$. Commelinaceae $(\mathrm{COE})$, Cyperaceae (CYP), Euphorbiaceae (EUP), Gramineae (GRA), Labiatae (LAB), Leguminosae (LEG), Malvaceae (MAL), Rubiaceae (RUB), Scrophulariaceae (SCR), Urticaceae (URT).

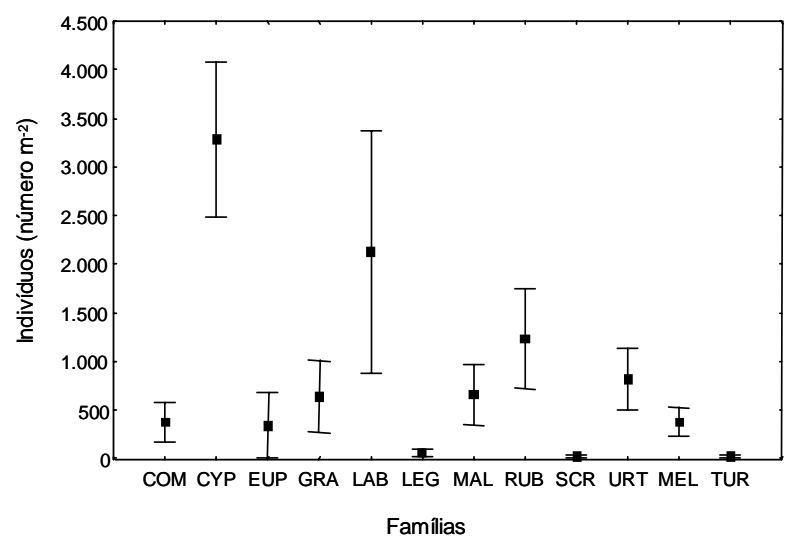

Figura 2 - Número médio de indivíduos por famílias em pastagem de B. humidicola de 4 anos de idade. Valores são média \pm erro-padrão $(\mathrm{n}=5)$. Compositae $(\mathrm{COM})$, Cyperaceae (CYP), Euphorbiaceae (EUP), Gramineae (GRA), Labiatae (LAB), Leguminosae (LEG), Malvaceae (MAL), Rubiaceae (RUB), Scrophulariaceae (SCR), Urticaceae (URT), Melastomataceae (MEL), Turneraceae (TUR). 
Na Figura 3, observa-se que na pastagem de $B$. humidicola de 15 anos de idade o número médio de indivíduos por famílias variou de 15,8 a 9947,2 por $\mathrm{m}^{2}$. A família Cyperaceae foi a mais numerosa, com 9.947,2 indivíduos por $\mathrm{m}^{2}$, seguida de Rubiaceae $(1.575,6)$, Labiatae $(572,1)$ e Euphorbiaceae $(318,3)$; as demais famílias apresentaram valores médios menores que 200 indivíduos por $\mathrm{m}^{2}$. A família com menor número médio de indivíduos foi Compositae, com 15,9 individuos por $\mathrm{m}^{2}$.

Na pastagem de $B$. humidicola de 20 anos de idade (Figura 4), o número médio de indivíduos por $\mathrm{m}^{2}$ variou de 15,9 a 525,2. A família que apresentou o maior número médio de indivíduos por $\mathrm{m}^{2}$ foi Cyperaceae $(525,2)$, seguida de Rubiaceae $(333,2)$, Malvaceae $(190,1)$ e Labiatae $(159,2)$; as demais famílias apresentaram valores médios menores que 40 indivíduos por $\mathrm{m}^{2}$. As famílias com menor número médio de indivíduos foram Euphorbiaceae,
Leguminosae, Sterculiaceae e Turneraceae, com 15,9 indivíduos por $\mathrm{m}^{2}$.

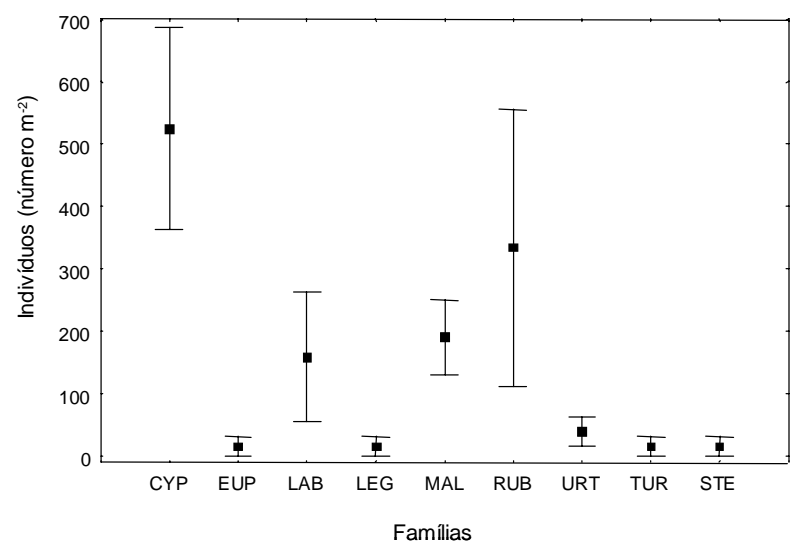

Figura 4 - Número médio de indivíduos por família em pastagem de B. humidicola de 20 anos de idade. Valores são média \pm erro-padrão $(\mathrm{n}=5)$. Cyperaceae $(\mathrm{CYP})$, Euphorbiaceae (EUP), Labiatae (LAB), Leguminosae (LEG), Malvaceae (MAL), Rubiaceae (RUB), Urticaceae (URT), Turneraceae (TUR), Sterculiaceae (STE).

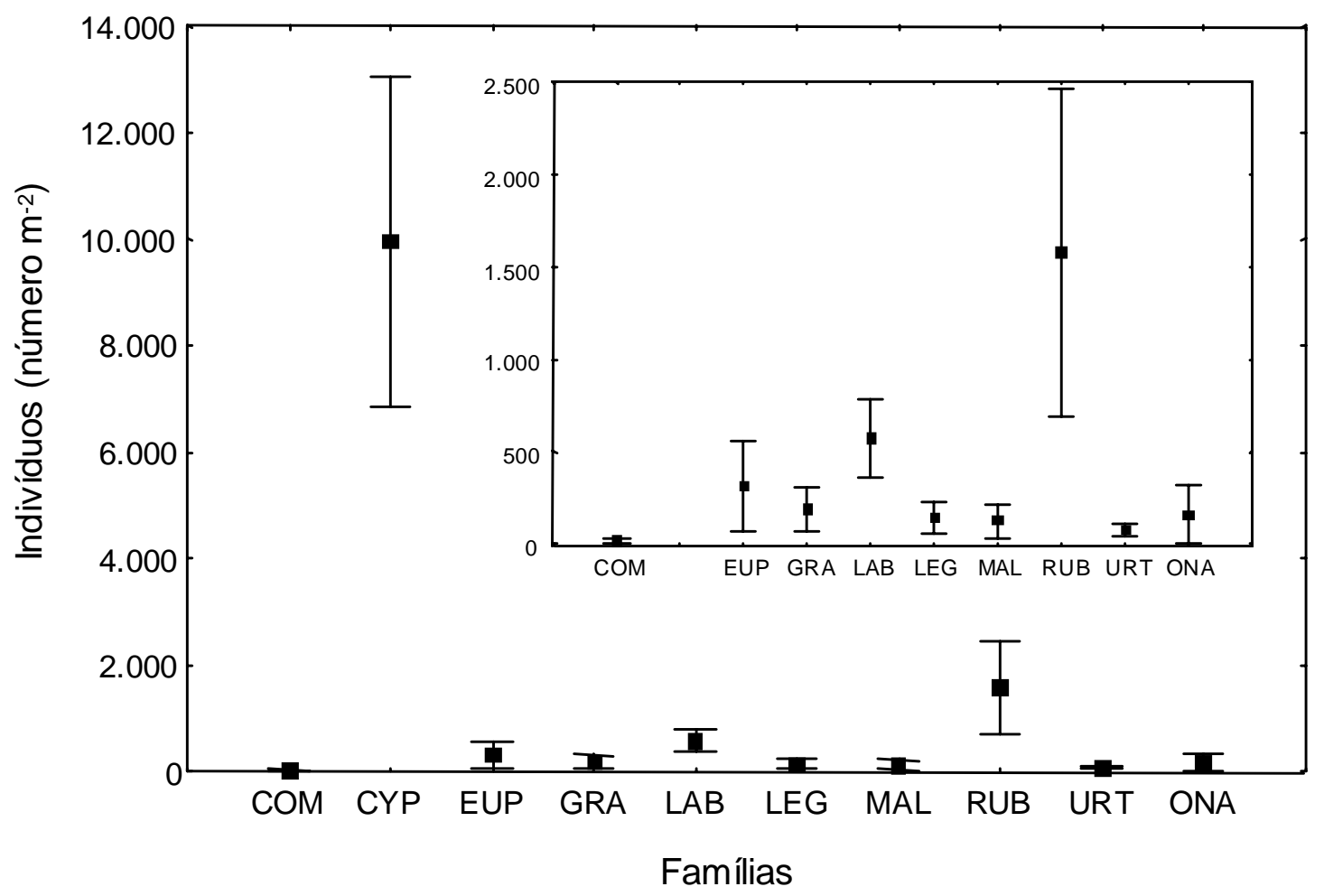

Figura 3 - Número médio de indivíduos por família em pastagem de B. humidicola de 15 anos de idade. No detalhe, o número médio de indivíduos nessa mesma pastagem, porém sem a família Cyperaceae (CYP), visando a melhor visualização da variação entre as demais famílias. Valores são média \pm desvio-padrão $(n=5)$. Compositae (COM), Cyperaceae (CYP), Euphorbiaceae (EUP), Gramineae (GRA), Labiatae (LAB), Leguminosae (LEG), Malvaceae (MAL), Rubiaceae (RUB), Urticaceae (URT), Onagraceae (ONA). 
Os resultados mostraram que as famílias Cyperaceae, Rubiaceae e Labiateae foram as de maior predominância em todas as pastagens estudadas. É possível que estas famílias tenham se destacado das demais devido à alta produção de sementes, aliada a outros mecanismos, como dormência, longevidade e dispersão, contribuindo, assim, para a ocorrência de grandes bancos de sementes no solo (Carmona, 1992). Dentre as famílias encontradas, Cyperaceae destacouse com apenas uma espécie representante (Cyperus diffusus), mostrando alta abundância no banco de sementes do solo em todas as pastagens estudadas. Barralis et al. (1988), estudando a longevidade de sementes de plantas daninhas anuais em solos cultivados, afirmaram que, em solos agrícolas, algumas espécies dominantes compõem $80 \%$ do banco de sementes do solo, sendo o restante constituído por sementes de uma grande variabilidade de espécies. No entanto, Wilson (1988) mostra que populações de sementes de plantas daninhas em solos cultivados são compostas freqüentemente de poucas espécies dominantes, apresentadas em grande número, e de numerosas espécies presentes em quantidades moderadas ou baixas.

Em levantamentos de plantas daninhas realizados em áreas de pastagem da Amazônia Brasileira, as famílias Euphorbiaceae (Dantas \& Rodrigues, 1980), Gramineae (Dantas \& Rodrigues, 1980; Mascarenhas et al., 1999) e Malvaceae (Dantas \& Rodrigues, 1980; Mascarenhas et al., 1999) também foram constatadas como freqüentes nas áreas estudadas.

Com base no banco de sementes do presente estudo, pode-se concluir que as pastagens estudadas, independentemente da idade e da espécie forrageira, apresentam grande potencial para serem infestadas por plantas daninhas, caso sejam expostas a situações que permitam que o solo destas fique desprotegido da cobertura vegetal da pastagem.

Pesquisas adicionais são necessárias para melhorar o entendimento dos processos que afetam o banco de sementes do solo de plantas daninhas em áreas de pastagem na Amazônia e de como este interage com outros fatores de manejo dessas plantas.

\section{AGRADECIMENTOS}

Aos proprietários Antônio Soares de Lima, Jonas Miranda de Araújo e Maria do Carmo
Nunes dos Santos, pela permissão da utilização de suas pastagens para acesso aos dados e realização deste estudo. Aos técnicos do Herbário da Embrapa Amazônia Oriental João A. Oliveira e Augusto César da Silveira Andrade, pelo competente auxílio na identificação das espécies e pela atenção durante a revisão bibliográfica, respectivamente. Ao pesquisador da Embrapa Amazônia Oriental Jonas Bastos da Veiga e ao Convênio Embrapa/ CIRAD, pelo excelente apoio logístico para a realização do trabalho. A um revisor anônimo, pelas sugestões dadas para a melhoria deste artigo científico.

\section{LITERATURA CITADA}

ARGEL, P.S.; KELLER-GREIN, G. Regional experience with Brachiaria: Tropical America Humid Lowlands. In: MILES, J.W.; MAASS, B.L.; VALLE, C.B., eds. Brachiaria: biology, agronomy and improvement. Cali: Centro Internacional de Agricultura Tropical. 1996. p.205-221.

BARRALIS, G.; CHADOEUF, R.; GOUET, J.P. Longévité des semences de mauvaises herbes annuelles dans un sol cultivé. Weed Res., v.28, p.407-418, 1988.

BASTOS, T.X. O clima da Amazônia brasileira segundo Koppen. Belém, IPEAN. B. Técnico, v.54, p.68-122, 1972.

BUHLER, D.D.; HASTZLER, R.G.; FORCELLA, F. Implications of weed seedbank dynamics to weed management. Weed Sci., v.45, p.329-336, 1997.

CARMONA, R. Problemática e manejo de banco de sementes de invasoras em solos agrícolas. Planta Daninha, v.10, p.5-16, 1992.

CARMONA, R. Banco de sementes e estabelecimento de plantas daninhas em agroecossistemas. Planta Daninha, v.13, p.3-9, 1995.

DANTAS, M.; RODRIGUES, I.A. Plantas invasoras de pastagens cultivadas na Amazônia. Belém: 1980, 23p. (EMBRAPA-CPATU. Boletim de Pesquisa, 1).

DIAS-FILHO, M.B. Limitações e potencial de Brachiaria humidicola para o trópico úmido brasileiro. Belém: EMBRAPA-CPATU, 1983. 28p. (EMBRAPA-CPATU. Documentos, 20). 
DIAS FILHO, M.B. Espécies forrageiras e estabelecimento de pastagens na Amazônia. In: PEIXOTO, A.M.; MOURA, J.C.; FARIA, V.P., eds. Pastagens na Amazônia. Piracicaba: FEALQ, 1986. p. 27-54.

DIAS-FILHO, M.B. Plantas invasoras em pastagens cultivadas da Amazônia: estratégias de manejo e controle. Belém: EMBRAPA-CPATU, 1990. 103p. (EMBRAPA - CPATU. Documentos, 52).

DIAS-FILHO, M.B. How is fecundity affected by mowing in the tropical weed Stachytarpeta cayennensis (Verbenaceae)? Pesq. Agropec. Bras., v.29, p.1675-1679, 1994.

DIAS-FILHO, M.B. Germination and emergence of Ipomoea asarifolia and Stachytarpeta cayennensis. Planta Daninha, v.14, p.118-126, 1996.

DIAS-FILHO, M.B. Alguns aspectos da ecologia de sementes de duas espécies de plantas invasoras da Amazônia brasileira: implicações para o recrutamento de plântulas em áreas manejadas. In: GASCON, C.; MOUTINHO, P., eds. Floresta amazônica: dinâmica, regeneração e manejo. Manaus: INPA, 1998a. p.233-248.

DIAS-FILHO, M.B. Pastagens cultivadas na Amazônia oriental brasileira: Processos e causas de degradação e estratégias de recuperação. In: DIAS, L.E.; MELLO, J.W.V., eds. Recuperação de áreas degradadas. Viçosa: UFV/Sociedade Brasileira de Recuperação de Áreas Degradadas, 1998b. p.135-47.
DIAS-FILHO, M.B. Potential for seed bank formation in two weedy species from Brazilian Amazonia. Planta Daninha, v.17, p.183-188, 1999.

MASCARENHAS, R.E.B.; MODESTO JÚNIOR, M.S.; DUTRA, S.; SOUZA FILHO, A.P.S.; TEIXEIRA NETO, J.F. Plantas daninhas de uma pastagem cultivada de baixa produtividade no nordeste paraense. Planta Daninha, v.17, p.399-418, 1999.

MIRITI, M.N. Regeneração florestal em pastagens abandonadas na Amazônia Central: Competição, predação e dispersão de sementes. In: GASCON, C. \& MOUTINHO, P., eds. Floresta amazônica: dinâmica, regeneração e manejo. Manaus: INPA, 1998. p.179-190.

THOMPSON, K. The functional ecology of seed banks. In: FENNER, M., ed. Seeds: The ecology of regeneration in plant communities. Wallingford: CAB International, 1992. p.231258.

UHL, C.; CLARK, K. Seed ecology of selected Amazon basin sucessional species. Bot. Gaz., v.144, p.419-425. 1983.

UHL, C.; BUSCHBACHER, R.; SERRÃO, E.A.S. Abandoned pastures in eastern Amazonia. I. patterns of plants succession. J. Ecol., v.76, p.663-681, 1988.

WILSON, R.G. Biology of weed seeds in the soil. In: ALTIERE, M.A., LIEBMAN, M., eds. Weed management in agroecosystems: ecological approaches. Boca Raton: CRC Press, 1988. p.2539. 